\title{
A INEFETIVIDADE DA LEGISLAÇÃO ACERCA DA INCLUSÃO DE CRIANÇAS COM DEFICIÊNCIA INTELECTUAL NO ENSINO REGULAR
}

\section{INEFFECTIVENESS OF THE LEGISLATION ON THE INCLUSION OF CHILDREN WITH INTELLECTUAL DISABILITY IN REGULAR EDUCATION}

Romulo André Alegretti de Oliveira Mestre em Direitos Sociais e Políticas Públicas pela Universidade de Santa Cruz do Sul- UNISC. Analista do MPU.

Fannie Moura de Fraga Acadêmica do Curso de direito da CNEC, campus Gravataí/RS.

Resumo: A legislação é explícita quanto à obrigatoriedade em acolher e matricular todos os alunos, assim como o disposto na Constituição Federal de 1988, independente de suas necessidades, ou diferenças. Entre- tanto, não é suficiente apenas esse acolhimento, mas que o aluno com necessidades especiais, mais especificamente portadores de deficiência intelectual, tenha condições de aprendizagem. Sendo assim, o presente en- 
Resumo: A legislação é explícita quanto à obrigatoriedade em acolher e matricular todos os alunos, assim como o disposto na Constituição Federal de 1988, independente de suas necessidades, ou diferenças. Entretanto, não é suficiente apenas esse acolhimento, mas que o aluno com necessidades especiais, mais especificamente portadores de deficiência intelectual, tenha condições de aprendizagem. Sendo assim, o presente ensaio busca compreender o processo de inclusão das crianças com deficiência intelectual, dando-se relevo pa- ra o disposto na legislação e a prática da inclusão no ensino regular.

Palavras-chave: Inclusão escolar. Necessidades especiais. Deficiência intelectual. Ensino regular.

\begin{abstract}
The law is explicit, as the obligation to receive and enroll all students, as well as the provisions of the 1988 Federal Constitution, regardless of their needs or differences. However, it is not enough only that host, but the student with special needs, specifically people with in-
\end{abstract}

1. Introdução - 2. Educação especial no Brasil - 2.1 Garantias ao aluno deficiente intelectual no ensino regular - 2.2 Garantias ao educador no ensino regular - 3. Acesso à educação: inclusão escolar - 3.1 Inclusão para o professor - 3.2 Inclusão para comunidade escolar - 4. Reflexos na prática da inclusão para a criança com deficiência intelectual: Estudo de caso - 4.1 Deficiência intelectual e inclusão - 4.2 Aspectos operacionais escolares na inclusão - 4.3 Reflexos no educador por conta da inclusão do educando - 4.4 Reflexos no educando deficiente intelectual - 4.5 Reflexos nos educandos sem deficiência intelectual - 5. Considerações finais - 6 . Referências

\section{INTRODUÇÃO}

Vivenciamos um momento em que se discute muito a inclusão escolar de alunos com deficiência intelectual na rede regular de ensino.

O direito à educação é garantido constitucionalmente e a inclusão de pessoas com deficiências intelectuais está prevista em diversas normativas ao longo dos últimos anos. Tal previsão legislativa se justifica, a título de exem- 
plo, pelo fato de que as crianças devem ser incluídas nas atividades sociais e de aprendizado, não sendo discriminadas por serem deficientes.

Para a devida inclusão, ao aluno devem ser garantidas bases de apoio no seu desenvolvimento psicossocial, bem como um monitor, salas multifuncionais, material didático adaptado a sua limitação e um profissional com especialização em Necessidades Especiais, ou curso de formação específica para atender de forma adequada as necessidades do aluno.

Porém, é sabido que a realidade é diversa às condições requeridas pela legislação, uma vez que as condições mínimas, por muitas vezes, não são atendidas e a inclusão na prática apresenta um rol de dificuldades. As instituições de ensino são insuficientes em diversos aspectos, como espaço, material didático específico e salas de aula devidamente equipadas.

A legislação é explícita, quanto à obrigatoriedade em acolher e matricular todos os alunos, assim como o disposto na Constituição Federal de 1988, independente de suas necessidades ou diferenças.

Entretanto, não é suficiente apenas esse acolhimento, mas que o aluno com necessidades especiais, mais especificamente portadores de deficiência intelectual, tenha condições de aprendizagem.

Sendo assim, o presente artigo busca compreender processo de inclusão, dividindo-se: primeiro em um breve percurso histórico mostrando como ocorreu ao longo dos anos a inclusão no Brasil e suas garantias legais em seguida, uma breve reflexão sobre o que é a inclusão para os diferentes protagonistas dessa realidade no ensino regular.

Por fim, apresentamos os dados coletados na visita in loco na Escola $\mathrm{Mu}-$ nicipal por Ciclos de Formação Duque de Caxias, RS, e o questionário realizado com o educador do menor com deficiência intelectual sobre a prática escolar e o processo de inclusão.

\section{EDUCAÇÃO ESPECIAL NO BRASIL}

O conceito de educação, mesmo muito complexo e abstrato, defini-se a partir de certa postura metodológica (OLIVEIRA, 2003).

Dentro do pensamento de Luhmann, a educação começa nos pilares da 
família, evoluindo posteriormente para a escola e a universidade. Nessa linha, a educação é um sistema social de interação, não devendo ser entendida apenas como um meio de transferência de conhecimento, mas sim como uma forma de fazer parte da sociedade e se auto compreender através da comunicação (OLIVEIRA apud LUHMANN, 2003).

Ainda no conceito de educação, Werner Jaeger (2001) publicou o livro Paideia, que conceitua o título como sendo o "processo de educação em sua forma verdadeira, a forma natural e genuinamente humana” na Grécia antiga.

O termo também significa a própria cultura construída a partir da educação. Era este o ideal que os gregos cultivavam do mundo, para si e para sua juventude. Uma vez que o governo próprio era muito valorizado pelos gregos, a Paideia combinava ethos, ou seja, hábitos que o fizessem ser digno e bom tanto para o governante quanto para o governado. Não tinha como objetivo ensinar ofícios, mas sim treinar a liberdade e nobreza. Paideia também pode ser encarada como o legado deixado de uma geração para outra na sociedade (JAEGER, 2001).

Além de formar o homem, a educação deve ainda formar o cidadão. A antiga educação, baseada na ginástica, na música e na gramática deixa de ser suficiente. Então nesse instante o ideal educativo grego aparece como Paideia, formação geral que tem por tarefa construir o homem como homem e como cidadão (JAEGER, 2001).

O conceito de Paideia em toda sua abrangência não designa unicamente ao meio de preparar a criança para a vida adulta. A ampliação do conceito fez com que ele passasse também a designar o resultado do processo educativo que se prolonga por toda vida, muito para além dos anos escolares (JAEGER, 2001).

As primeiras regulamentações em torno do direito das pessoas com deficiência à inclusão educacional estavam previstas na Constituição do Brasil, em 1824, influenciadas por ideias trazidas da França (ARANHA, 2005).

Inspirados por experiências realizadas por multiespecialistas da Europa e dos Estados Unidos, alguns brasileiros iniciaram a organização de servi- 
ços voltados para atendimento das pessoas com necessidades especiais (ARANHA, 2005).

Na década de 1930, o Brasil entrou no período de institucionalização que, segundo Aranha (2005), foi caracterizada "pela retirada das pessoas com deficiência de suas comunidades de origem e pela manutenção delas em instituições residenciais segregadas ou escolas especiais, frequentemente situadas em localidades distantes de suas famílias".

A educação, que era parte fundamental neste processo, teve que sofrer uma radical transformação. Em todo o mundo, até aquele momento, as pessoas com deficiência haviam sido colocadas à margem da educação: o aluno com deficiência, particularmente, era atendido apenas em separado ou simplesmente excluído do processo educativo que tinha por premissa que os alunos deveriam obedecer a padrões de normalidade (BRAGA, 2010).

Em 1926, na cidade de Porto Alegre, RS, foi criado o Instituto Pestalozzi, por Tiago e Johanna Würtho, possuidor até hoje de um importante papel no atendimento aos alunos com deficiência mental. De acordo com Mazzotta (2008), o casal de professores inspiravam-se na concepção da pedagogia social desenvolvida pelo educador suíço João Henrique Pestalozzi.

Além da Sociedade Pestalozzi, passam a existir outras instituições de natureza filantrópica, sem fins lucrativos, como as Associações de Pais e Amigos dos Excepcionais (APAES), que oferecem atendimento à pessoa com deficiência mental com auxílio de seus parentes e comunidade.

Em dezembro de 1954, inspirado no movimento americano para defender os interesses e necessidades de seus filhos com deficiência, surgiu no Brasil, na cidade do Rio de Janeiro, a primeira APAE, com o apoio do casal norte-americano George Bemis e Beatrice Bemis, membros da National Association For Retarded Children - NARC. Dessa forma, pouco a pouco começa a emergir um trabalho mais educacional do que médico para o atendimento das pessoas com deficiência mental, servindo de referência à nível 
REVISTA DA ESDM - 2016-V.2-N.04

nacional, sendo mais de duas mil sedes espalhadas pelo Brasil (ARANHA, 2005).

Em 1988, a nova Constituição Federal do Brasil, segundo Mendes (2006), traçou as linhas mestras visando a democratização da educação brasileira, garantindo para as pessoas com deficiência o direito à educação, destacando-se que esta deve ocorrer preferencialmente na rede regular de ensino.

Art. 208. O dever do estado com a educação será efetivada mediante a garantia de:

$[\ldots]$

III - atendimento educacional especializado aos portadores de deficiência, preferencialmente na rede regular de ensino.

Alguns anos após já se fala em educação para todos, a nível nacional, com a proposta de professores especializados para atendimento às crianças com necessidades especiais, destacando novamente que este deve se dar na rede regular de ensino, à luz da Constituição Federal de 88:

A Educação como direito fundamental para todos, no Brasil, foi aprovada a partir da Lei de Diretrizes e Bases. A Lei n. ${ }^{\circ}$ 9.394, de 20 de dezembro de 1996, nos seus artigos 58, 59 e 60 regulamenta que a Educação Especial é uma modalidade de educação escolar, e garante às pessoas com deficiência o direito de frequentar a sala de aula comum do ensino regular, destacando que o atendimento a esses alunos deve acontecer "preferencialmente na rede regular de ensino". Evidencia, ainda, que o atendimento educacional será realizado em "classes, escolas ou serviços especializados", sempre que, por conta das condições específicas do aluno com deficiência, não for possível integrá-lo nas classes regulares de ensino, e que os sistemas de ensino assegurarão, para essas pessoas, professores com especialização 
adequada para atuar no Atendimento Educacional Especializado - AEE e no ensino regular (VALERA, 2015).

No sentido de firmar a preferência de educação para crianças com deficiência intelectual dentro do ensino regular, em 1994 a Declaração de Salamanca proclamou:

2. Acreditamos e Proclamamos que:

- toda criança tem direito fundamental à educação, e deve ser dada a oportunidade de atingir e manter o nível adequado de aprendizagem;

- toda criança possui características, interesses, habilidades e necessidades de aprendizagem que são únicas;

- sistemas educacionais deveriam ser designados e programas educacionais deveriam ser implementados no sentido de se levar em conta a vasta diversidade de tais características e necessidades;

- aqueles com necessidades educacionais especiais devem ter acesso à escola regular, que deveria acomodá-los dentro de uma Pedagogia centrada na criança, capaz de satisfazer a tais necessidades;

- escolas regulares que possuam tal orientação inclusiva constituem os meios mais eficazes de combater atitudes discriminatórias criando-se comunidades acolhedoras, construindo uma sociedade inclusiva e alcançando educação para todos; além disso, tais escolas provêm uma educação efetiva à maioria das crianças e aprimoram a eficiência e, em última instância, o custo da eficácia de todo o sistema educacional.

Mesmo a preferência de atendimento educacional sendo na rede de ensino regular, há ressalva quanto às dificuldades estabelecidas pela condição específica do aluno a ser incluído, tornando mais atrativo o ideal de um cen- 
tro especializado de atendimento para alunos com deficiências do que integra-lo em uma sala de aula regular.

A Convenção sobre os direitos das pessoas com deficiência outorgada pela Organização das Nações Unidas - ONU em 2006 é ratificada pelo Brasil como emenda constitucional, por meio do decreto Legislativo 186/2008 e pelo Decreto Executivo 6949/2009. Este documento sistematiza estudos e debates mundiais realizados ao longo da última década do séc. XX e nos primeiros anos deste século, criando uma conjuntura favorável à definição de políticas públicas fundamentadas no paradigma da inclusão social.

\subsection{Garantias ao aluno deficiente intelectual no ensino regular}

O principal personagem dentro do assunto inclusão é o deficiente. Conforme passaram-se os anos a sociedade despertou para a necessidade de legislar garantias a essa parcela da população, entendendo que a história já negligenciou o bastante.

A deficiência intelectual é uma das mais comuns encontradas em crianças. Caracterizada pela redução no desenvolvimento cognitivo, acarreta, muitas vezes, um desenvolvimento mais lento na fala, no desenvolvimento neuropsicomotor e em outras habilidades.

Em geral, pessoas com desenvolvimento típico são capazes de contar e de fazer cálculos envolvendo operações matemáticas simples mesmo antes de entrarem na escola. Diferentemente dessas, no entanto, pessoas com atraso no desenvolvimento intelectual apresentam com muita frequência dificuldades na aquisição dessas habilidades mesmo após muitos anos de instrução escolar especializada (ESCOBAL; ROSSIT; ROYOS, 2010).

Entende-se então que a deficiência intelectual é associada à dificuldade de aprendizado. Uma criança com um QI muito baixo. 
Funcionamento intelectual subnormal que se origina durante o período de desenvolvimento. Possui múltiplas etiologias potenciais, incluindo defeitos genéticos e lesões perinatais. As pontuações do quociente de inteligência (QI) são comumente utilizadas para determinar se um indivíduo possui deficiência intelectual. As pontuações de QI entre 70 e 79 estão na margem da faixa de retardo mental. As pontuações abaixo de 67 estão na faixa de retardo (JOYNT, 1992).

Atualmente existem vários regulamentos acerca do assunto visando atender as peculiaridades de cada portador de necessidades especiais.

Com esse foco, o Decreto $\mathrm{n}^{\mathrm{o}} 6.253$ de 2007 possibilita ao aluno deficiente a dupla matrícula no ensino regular e, também, estende o atendimento educacional especializado á instituições comunitárias com atuação exclusiva na educação especial, desde que conveniadas com o Poder Executivo.

Art. 9. -A. Para efeito da distribuição dos recursos do FUNDEB, será admitida a dupla matrícula dos estudantes da educação regular da rede pública que recebem atendimento educacional especializado.

$\$ 1 .^{\circ}$ A dupla matrícula implica o cômputo do estudante tanto na educação regular da rede pública, quanto no atendimento educacional especializado.

$\$ 2 .^{\circ} \mathrm{O}$ atendimento educacional especializado aos estudantes da rede pública de ensino regular poderá ser oferecido pelos sistemas públicos de ensino ou por instituições comunitárias, confessionais ou filantrópicas sem fins lucrativos, com atuação exclusiva na educação especial, conveniadas com o Poder Executivo competente, sem prejuízo do disposto no Art. 14. 
Com relação à idade de permanência no ensino fundamental, é garantido ao aluno com deficiência intelectual, atendimento com prioridade de escolarização até que seja completada a idade máxima de 15 (quinze) anos completos, que idade mínima para ingresso nos cursos de EJA, bem como o disposto no artigo $4 .^{\circ}$, incisos I e VII, da Lei n. ${ }^{\circ}$ 9.394/96:

Art. $4 .^{\circ} \mathrm{O}$ dever do Estado com educação escolar pública será efetivado mediante a garantia de:

I - educação básica obrigatória e gratuita dos 4 (quatro) aos 17 (dezessete) anos de idade, organizada da seguinte forma:

a) pré-escola;

b) ensino fundamental;

c) ensino médio;

$[\ldots]$

VII - oferta de educação escolar regular para jovens e adultos, com características e modalidades adequadas às suas necessidades e disponibilidades, garantindo-se aos que forem trabalhadores as condições de acesso e permanência na escola.

A Resolução CNE/CEB n. ${ }^{\circ} 3$ de 2010, em seu artigo 5. ${ }^{\circ}$, complementa:

Art. $5 .^{\circ}$ Obedecidos o disposto no artigo $4 .^{\circ}$, incisos I e VII, da Lei n. ${ }^{\circ}$ 9.394/96 (LDB) e a regra da prioridade para o atendimento da escolarização obrigatória, será considerada idade mínima para os cursos de EJA e para a realização de exames de conclusão de EJA do Ensino Fundamental a de 15 (quinze) anos completos.

O Ministério da Educação, por intermédio da Secretaria de Educação Especial, considerando a Constituição Federal de 1988, que estabelece o direi- 
to de todos á educação, visa o Atendimento Educacional Especializado AEE na educação básica como direito aos alunos com deficiência intelectual, conforme o exposto anteriormente (XAVIER, 2015).

Desse modo, compreende que a educação inclusiva é uma modalidade que perpassa todos os níveis de ensino da educação básica ao ensino superior. Assim terá o direito a esta modalidade de ensino todos os alunos que se possuírem deficiência intelectual.

O ensino oferecido no AEE é diferente do ensino escolar, e não pode ser visto como um espaço onde se tem reforço escolar ou complementação das atividades escolares. São exemplos práticos de Atendimento Educacional Especializado a formação do aluno para a utilização dos recursos tecnológicos, comunicação alternativa, disponibilização e preparação de materiais pedagógicos acessíveis ao aluno com deficiência intelectual (XAVIER, 2015).

Em vista disso, os sistemas de ensino devem disponibilizar os recursos da educação especial para que os alunos tenham os recursos e as condições de acesso ao currículo, promovendo os materiais didáticos, aos espaços e equipamentos, aos sistemas de comunicação e informação e ao conjunto das atividades escolares (XAVIER, 2015).

O AEE tem por intenção organizar e elaborar recursos pedagógicos que promovem a acessibilidade e que acabar com as barreiras para a construção da aprendizagem plena e, integrando e proporcionando a participação dos alunos. Ponderando a particularidades das necessidades e limites individuais dos alunos.

De acordo com o Decreto 7611/11é garantida também uma rede de apoio, no âmbito da atuação intersetorial, da formação docente, do acesso a recursos, serviços e equipamentos, entre outros que contribuam para a realização do AEE.

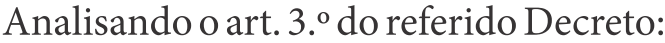

Art. 3. ${ }^{\circ}$ São objetivos do atendimento educacional especializado: 
I - prover condições de acesso, participação e aprendizagem no ensino regular e garantir serviços de apoio especializados de acordo com as necessidades individuais dos estudantes;

II - garantir a transversalidade das ações da educação especial no ensino regular;

III - fomentar o desenvolvimento de recursos didáticos e pedagógicos que eliminem as barreiras no processo de ensino e aprendizagem; e

IV - assegurar condições para a continuidade de estudos nos demais níveis, etapas e modalidades de ensino.

O aluno com deficiência intelectual deve ter todo o apoio para que haja continuidade no seu ensino. O Decreto prevê que cada etapa e auxílio especializado têm de atender as necessidades individuais de cada estudante, suas peculiaridades.

Ainda no Decreto, é apontado que os professores devem ter uma formação inicial que o habilite para o exercício da docência e formação específica na educação especial, inicial ou continuada para atuação no AEE.

Art. 5. ${ }^{\circ} \mathrm{A}$ União prestará apoio técnico e financeiro aos sistemas públicos de ensino dos Estados, Municípios e Distrito Federal, e a instituições comunitárias, confessionais ou filantrópicas sem fins lucrativos, com a finalidade de ampliar a oferta do atendimento educacional especializado aos estudantes com deficiência, transtornos globais do desenvolvimento e altas habilidades ou superdotação, matriculados na rede pública de ensino regular.

$\S 1 .^{\circ}$ As instituições comunitárias, confessionais ou filantrópicas sem fins lucrativos de que trata o caput devem ter atuação na educação especial e serem conveniadas com o Poder Executivo do ente federativo competente. 
$\$ 2 .^{\circ} \mathrm{O}$ apoio técnico e financeiro de que trata o $\mathbf{c a}$ put contemplará as seguintes ações:

I - aprimoramento do atendimento educacional especializado já ofertado;

II - implantação de salas de recursos multifuncionais;

III - formação continuada de professores, inclusive para o desenvolvimento da educação bilíngue para estudantes surdos ou com deficiência auditiva e do ensino do Braile para estudantes cegos ou com baixa visão;

IV - formação de gestores, educadores e demais profissionais da escola para a educação na perspectiva da educação inclusiva, particularmente na aprendizagem, na participação e na criação de vínculos interpessoais;

Ainda nesse mesmo sentido temos:

IV - Objetivo da Política Nacional de Educação Especial na Perspectiva da Educação Inclusiva

A Política Nacional de Educação Especial na Perspectiva da Educação Inclusiva tem como objetivo o acesso, a participação e a aprendizagem dos alunos com deficiência, transtornos globais do desenvolvimento e altas habilidades/superdotação nas escolas regulares, orientando os sistemas de ensino para promover respostas às necessidades educacionais especiais, garantindo:

Transversalidade da educação especial desde a educação infantil até a educação superior;

Atendimento educacional especializado; 
Continuidade da escolarização nos níveis mais elevados do ensino;

Formação de professores para o atendimento educacional especializado e demais profissionais da educação para a inclusão escolar.

Retornando ao Artigo 5. ${ }^{\circ}$, do Decreto anteriormente mencionado, há uma síntese dos objetivos do que seriam as salas de recursos multifuncionais:

3. As salas de recursos multifuncionais são ambientes dotados de equipamentos, mobiliários e materiais didáticos e pedagógicos para a oferta do atendimento educacional especializado.

A Sala de Recursos Multifuncionais será o local apropriado para o aluno com deficiência aprender como utilizar as ferramentas de tecnologias assistiva, com vista ao desenvolvimento da sua autonomia levando em consideração que o recurso de tecnologia assistiva vai além das salas multifuncionais.

A tecnologia assistiva é uma área do conhecimento, de característica interdisciplinar, que engloba produtos, recursos, metodologias, estratégias, práticas e serviços que objetivam promover a funcionalidade, relacionada à atividade e participação, de pessoas com deficiência, incapacidades ou mobilidade reduzida, visando sua autonomia, independência, qualidade de vida e inclusão social.

A tecnologia assistiva é um recurso utilizado para possibilitar a execução de uma atividade pretendida ou necessária a uma pessoa com deficiência. Na perspectiva da Educação Inclusiva a tecnologia assistiva favorece a participação do aluno com deficiência em diversas atividades escolares ligadas aos objetivos educacionais comuns (SARTORETTO, 2014).

Podemos citar como exemplo de tecnologia assistiva os materiais escolares e pedagógicos acessíveis, a comunicação alternativa, os recursos de acessibilidade ao computador, localização e sinalização, dentre outros (XAVIER, 2015).

Segundo Mazzotta (1996), o atendimento as necessidades educacionais especiais na classe e ou a utilização de todo conhecimento acumulado pela 
área de educação especial, proporcionará a melhoria da qualidade de ensino segundo as características de cada aluno, visando a um atendimento individualizado, organiza os currículos, sendo garantidor dos direitos do menor com deficiência intelectual, visando diversificar a metodologia e as estratégias de ensino entre tantas modificações e com certeza benéfica para todos os educandos.

\subsection{GARANTIAS AO EDUCADOR NO ENSINO REGULAR}

O professor que tiver em sala de aula um aluno com deficiência intelectual deverá estar capacitado para trabalhar as dificuldades e limitações do aluno de inclusão.

É de extrema importância que o profissional da educação seja capacitado, para ter confiança e preparo para lidar com as situações advindas de um cotidiano da inclusão, sem que esse aluno seja negligenciado, nem os demais alunos sem deficiências.

Art. 59 Os sistemas de ensino assegurarão aos educandos com deficiências, transtornos globais do desenvolvimento e altas habilidades ou superdotação:

[...]

III. Professores com especialização adequada em nível médio ou superior, para atendimento especializado, bem como professores de ensino regular capacitados para a integração desses educandos nas classe comuns.

Ou seja, não é apenas um direito do aluno, mas também do educador, que precisa se sentir preparado e seguro para lidar com esses desafios.

O texto do Despacho n. ${ }^{\circ}$ 14.026/2007 diz:

5.4 - As turmas com alunos com necessidades educativas especiais resultantes de deficiências ou incapacidade comprovadamente inibidora da sua formação de qualquer nível de ensino são constituí- 
das por 20 alunos, não podendo incluir mais de 2 alunos nestas condições.

Sendo assim, as turmas com alunos com necessidades especiais devem ser reduzidas.

Cabe aos sistemas de ensino, ao organizar a educação especial na perspectiva da educação inclusiva, disponibilizar as funções de instrutor, tradutor/intérprete de Libras e guiaintérprete, bem como de monitor ou cuidador dos alunos com necessidade de apoio nas atividades de higiene, alimentação, locomoção, entre outras, que exijam auxílio constante no cotidiano escolar.

Para que haja melhor amparo ao professor, é garantido um monitor, também especializado, que se dedicará a auxiliar o professor no trato com o menor com deficiência e que auxiliará o menor, para que este possa concluir suas tarefas e tenha maior desenvolvimento cognitivo e de aprendizagem.

\section{ACESSO À EDUCAÇÃO: INCLUSÃO ESCOLAR}

O princípio da isonomia, ou da igualdade, liga-se ao princípio da dignidade da pessoa humana, pelo qual, todos os cidadãos possuem direitos, uma vez que são dotados de humanidade, devendo assim, serem tratados de forma igualitária independente de sua origem, raça, gênero ou particularidades.

O princípio da igualdade está legitimado já no preâmbulo do texto constitucional. Logo em seguida, no artigo $5 .^{\circ}$, a nobre Constituição Federativa do Brasil (1988), positiva que:

Art. 5. ${ }^{\circ}$ Todos são iguais perante a lei, sem distinção de qualquer natureza, garantindo-se aos brasileiros e aos estrangeiros residentes no país a inviolabilidade do direito à vida, à liberdade, à igualdade, à segurança e à propriedade.

Em seguida, ainda na Constituição, o Artigo 19 dispõe assim: 
Art. 19. É vedado à União, aos Estados, ao Distrito Federal e aos municípios:

$[\ldots]$

III - Criar distinções entre brasileiros ou preferências entre si.

Segundo Mello (1999), a Lei não pode assegurar privilégios, devendo ser instrumento que regula a vida social tratando de forma equitativa todos os cidadãos. Afirma, ainda, que esse deve ser o conteúdo "político-ideológico absorvido pelo princípio da isonomia e juridicizado pelos textos constitucionais em geral, ou de todo modo assimilado pelos sistemas normativos vigente.

Considerando os artigos anteriores, incluindo os que se referem ao direito à educação e os que remetem ao princípio da igualdade, o princípio da igualdade é o alicerce da inclusão. Assim como a política de quotas, que vem de encontro ao entendimento da necessidade de garantir a todos o acesso a educação de qualidade.

Dentro do pensamento da pedagogia, mais precisamente no conceito de Piaget, para ocorrer a educação inclusiva, deve-se compreender como a criança aprende, como um referencial para saber até onde ela consegue evoluir. Assim o professor conseguirá respeitar às condições intelectuais do aluno, entendendo suas atitudes em sala de aula para melhor trabalhar com elas (PIAGET; GRÉCO, 1974).

Sendo assim, a avaliação dos limites de cada aluno, proporcionaria uma possibilidade de aprendizagem quase em mesmo nível, respeitando a forma como cada individuo pode alcançar esses resultados.

A partir da Declaração de Salamanca, tem-se uma visão mundial da inclusão na garantia do direito de igualdade. Em seu texto disponível pelo MEC traz a seguinte explicação no item $n .{ }^{\circ}$ 9:

9. A situação com respeito à educação especial varia enormemente de um país a outro. Existem por exemplo, países que possuem sistemas de escolas especiais fortemente estabelecidos para aqueles que possuam impedimentos específicos. Tais escolas es- 
peciais podem representar um valioso recurso para o desenvolvimento de escolas inclusivas. Os profissionais destas instituições especiais possuem nível de conhecimento necessário à identificação precoce de crianças portadoras de deficiências. Escolas especiais podem servir como centro de treinamento e de recurso para os profissionais das escolas regulares. Finalmente, escolas especiais ou unidades dentro das escolas inclusivas podem continuar a prover a educação mais adequada a um número relativamente pequeno de crianças portadoras de deficiências que não possam ser adequadamente atendidas em classes ou escolas regulares. Investimentos em escolas especiais existentes deveriam ser canalizados a este novo e amplificado papel de prover apoio profissional às escolas regulares no sentido de atender às necessidades educacionais especiais. Uma importante contribuição às escolas regulares que os profissionais das escolas especiais podem fazer refere-se à provisão de métodos e conteúdos curriculares às necessidades individuais dos alunos.

A luz da Educação Especial na Perspectiva da Inclusão Escolar, publicada pelo MEC:

A escola comum se torna inclusiva quando reconhece as diferenças dos alunos diante do processo educativo e busca a participação e o progresso de todos, adotando novas práticas pedagógicas.

Logo, a inclusão vai além de colocar o aluno com deficiência dentro da sala de aula, sendo comum esta prática de forma integratória, em vez de inclusiva, o que é insuficiente para o desenvolvimento cognitivo do menor.

Faz-se necessário, uma mudança de paradigma dos sistemas educacionais onde o foco é o deficiente intelectual, levando em conta sua capacidade geral e não apenas as disciplinas obrigatórias e resultados quantitativos, que 
favorecem apenas uma parte dos alunos (TÉDDE, 2014).

A ideia de uma escola inclusiva se fundamenta numa filosofia que reconhece e valoriza a diversidade, como característica inerente à constituição de qualquer sociedade. Partindo desse princípio e tendo como norte os Direitos Humanos, há necessidade de se garantir o acesso e a participação de todos, a todas as oportunidades, independentemente das peculiaridades de cada individuo (PEREIRA, 2008).

Segundo Pereira:

O paradigma da inclusão vem ao longo dos anos, buscando a não exclusão escolar e propondo ações que garantam o acesso e permanência do aluno com deficiência no ensino regular.

No entanto, o paradigma da segregação é forte e enraizado nas escolas e com todas as dificuldades e desafios a enfrentar, acabam por reforçar o desejo de mantê-los em espaços especializados.

A tendência é focar as deficiências dos nossos sistemas educacionais no desenvolvimento pleno da pessoa, onde se fala em fracasso escolar, no déficit de atenção na hiperatividade e nas deficiências onde o problema fica centrado na incompetência do aluno. Isso é cultura na escola, onde não se pensa como está se dando esse processo ensino-aprendizagem e qual o papel do professor no referido processo. Temos que refletir sobre a educação em geral para pensarmos em inclusão da pessoa com deficiência.

Há também que se lembrar que todos os alunos vêm com conhecimentos de realidade que não pode ser desconsiderado, pois faz parte de sua história de vida, exigindo uma forma diferenciada no sistema de aprendizagem. 
Mas temos que pensar que para que a inclusão se efetue, não basta estar garantido na legislação, mas demanda modificações profundas e importantes no sistema de ensino. Essas mudanças deverão levar em conta o contexto socioeconômico, além de serem gradativas, planejadas e contínuas para garantir uma educação de ótima qualidade.

Portanto, a inclusão depende de mudança de valores da sociedade que não se faz com recomendações técnicas, como se fossem receitas de bolo, mas com reflexões dos professores, direções, pais, alunos e comunidade. Contudo essa questão não é tão simples, pois, devemos levar em conta as diferenças de cada indivíduo (PEREIRA, 2008).

Temos que diferenciar a integração da inclusão, na qual a integração depende do aluno e ele é que tem que se adaptar buscando alternativas para se integrar, ao passo que na inclusão, o social deverá modificar-se e prepararse para receber o aluno com deficiência.

No entanto, a realidade fática desse processo inclusivo demonstra variadas contingências no âmbito escolar, de modo que requer muitas discussões relativas ao tema, com relevo também para a legislação existente.

\subsection{INCLUSÃO PARA O PROFESSOR}

O papel do professor nesse processo de inclusão é fundamental, uma vez que, ele é o mediador do processo ensino/aprendizagem. Mantoan (1997) afirma que é necessário recuperar, urgentemente, a confiança dos professores em saberem lidar e desenvolver o processo de ensino e aprendizagem com todos os alunos, sem exceções. Para isso, é oportuno possibilitar aos docentes a participação em cursos que discutam estratégias educacionais visando à participação ativa e consciente de todos os alunos no processo de ensino-aprendizagem. Esses cursos devem atender as necessidades de preparo que os professores têm para desenvolver práticas docentes realmente inclusivas.

A falta de preparo do educador o faz temer a inclusão frente ao desco- 
nhecimento de métodos pedagógicos adequados para ensinar ao aluno especial e compreender suas limitações e especialidades.

Não só o professor, mas todos os profissionais da educação dentro da prática pedagógica possuem um papel importante dentro da inclusão. Cabe o trecho da Declaração de Salamanca (1994), que destaca: “A preparação adequada de todo o pessoal da educação constitui um fator-chave na promoção do progresso em direção às escolas inclusivas".

Dentro deste pensamento, muito complexo, recai uma enorme carga de responsabilidade sobre o educador. Expectativas que serão concretas apenas com a constituição de uma equipe interdisciplinar que auxilie e trabalhe em conjunto com o professor na composição de uma prática inclusiva. Porém, é sabido que na maioria dos casos, esta prática é estabelecida como um último recurso, apenas quando há um esgotamento de tentativas por esse profissional.

Mesmo assim, esta proposta caminha contra a inclusão já que coloca uma divisão entre o aluno com necessidades especiais e o aluno que não precisa de apoio pedagógico, contribuindo para que a inserção seja dificultosa. É preciso considerar que não só o aluno necessita ser incluído, mas o grupo do qual participará também.

Como aponta Páez (2001), atender à diversidade é atender as crianças com deficiências, mas também todas as outras diversidades que aparecem cotidianamente na comunidade em que vivem.

O Documento Subsidiário à Política de Inclusão esclarece:

A partir da LDBEN 9394/96, a Educação Especial é definida como uma modalidade de educação escolar que permeia todas as etapas e níveis de ensino. Esta definição permite desvincular "educação especial" de "escola especial". Permite também, tomar a educação especial como um recurso que beneficia a todos os educandos e que atravessa o trabalho do professor com toda a diversidade que constitui o seu grupo de alunos. 
Os educadores precisam compreender que só existirá inclusão de pessoas com necessidades especiais em suas dependências se todos estiverem empenhados em contribuir para a edificação de um trabalho mais humano e acolhedor. Na quebra de paradigmas é fundamental a todo ser humano o respeito à diferença (BRAGA, 2010).

Devemos considerar também os conflitos que se estabelecem nas relações frente às questões relativas à gratificação no plano salarial e o aumento no trabalho para os professores do ensino regular.

\subsection{INCLUSÃO PARA COMUNIDADE ESCOLAR}

A educação inclusiva, diferentemente da educação tradicional, na qual todos os alunos é que precisavam se adaptar a ela, estabelece um novo modelo onde a escola é que precisa se adaptar às necessidades e especificidades do aluno, buscando além de sua permanência na escola, o seu máximo desenvolvimento. Ou seja, na educação inclusiva, uma escola deve se preparar para enfrentar o desafio de oferecer uma educação com qualidade para todos os seus alunos. Considerando que numa escola, cada aluno apresenta características próprias, constituindo uma diversidade de ritmos de aprendizagem, o desafio da escola hoje é trabalhar com essa diversidade (FRIAS, 2008).

Nas várias reformas educacionais ocorridas no país nos últimos anos, com destaque para a nova Lei de Diretrizes e Bases da Educação Nacional, de 1996, o tema das necessidades educativas especiais esteve presente, com a referência comum da responsabilidade do poder público e da matrícula preferencial na rede regular de ensino, com os apoios especializados necessários.

Com a Resolução n. ${ }^{\circ}$ 2/2001que instituiu as Diretrizes Nacionais para a Educação Especial na Educação Básica, houve um avanço na perspectiva da universalização e atenção à diversidade, na educação brasileira, com a seguinte recomendação, em seu Art. 2.

Os sistemas de ensino devem matricular todos os 
alunos, cabendo às escolas organizar-se para o atendimento aos educandos com necessidades educacionais especiais, assegurando as condições necessárias para a educação de qualidade para todos.

Hoje, os deficientes possuem seus direitos assegurados pela Lei de Diretrizes e Bases da Educação (LDB) 9.394/96, como vemos nos Artigos 58, 59.

Como podemos ver no Art. 58 dessa mesma Lei, a educação escolar preferencialmente deve ser oferecida na rede regular de ensino, para todos os alunos deficientes. O Artigo 58 refere-se assim:

$\$ 1 .^{\circ}$ Haverá, quando necessário, serviços de apoio especializado, na escola regular, para atender às peculiaridades da clientela de educação especial. $\$ 2 .^{\circ}$. $\mathrm{O}$ atendimento educacional será feito em classes, escolas ou serviços especializados, sempre que, em função das condições específicas dos alunos, não for possível a sua integração nas classes comuns de ensino regular.

Artigo 59 que propõe:

Art. 59 Os sistemas de ensino assegurarão aos educandos com deficiências, transtornos globais do desenvolvimento e altas habilidades ou superdotação:

I. Currículos, métodos, técnicas educativas e organização específica, para atender às suas necessidades;

II. Terminalidade específica para aqueles que não puderem atingir o nível exigido para a conclusão do ensino fundamental, em virtude de suas deficiências, e aceleração para concluir em menor tempo o programa escolar para os superdotados;

III. Professores com especialização adequada em nível médio ou superior, para atendimento espe- 
cializado, bem como professores de ensino regular capacitados para a integração desses educandos nas classe comuns;

IV. Educação especial para o trabalho, visando a sua integração na vida em sociedade, inclusive condições adequadas para os que não revelarem capacidade de inserção no trabalho competitivo, mediante articulação com os órgãos oficiais afins, bem como para aqueles que apresentam uma habilidade superior nas áreas artísticas, intelectual ou psicomotora;

$\mathrm{V}$. acesso igualitário aos benefícios dos programas sociais suplementares disponíveis para o respectivo nível do ensino regular.

Segundo o entendimento de Mantoan (1997), a Inclusão de alunos com necessidades educacionais especiais é um movimento que tem sido muito polemizado por diferentes segmentos, mas essa inserção nada mais é do que garantir o direito constitucional que todos independentes de suas necessidades, têm a uma educação de qualidade, e que a Inclusão vai depender da capacidade de lidarmos com a diversidade e as diferenças.

De um modo geral, as escolas têm conhecimento das leis acerca da inclusão bem como, da obrigatoriedade da garantia de vaga para os alunos com necessidades educacionais especiais, no entanto não há sustentação necessária, como por exemplo, a ausência de definições mais estruturais acerca da educação especial e dos suportes necessários a sua implementação.

Sabemos também, da dura realidade das condições de trabalho e os limites da formação profissional, o número elevado de alunos por turma, a rede física inadequada, o despreparo para ensinar "alunos especiais". Sabemos que, para que a inclusão se efetue não basta a garantia apenas na legislação, mas demanda modificações profundas e importantes no sistema de ensino. Essas mudanças deverão levar em conta o contexto socioeconômico, além de serem gradativas, planejadas e contínuas para garantir uma educação de ótima qualidade. 
Por outro lado, o processo de Inclusão já está posto e não se trata de desativar o que está funcionando, mas sim de buscarem alternativas e formas de articulações que possibilitem esse novo modo de ver e pensar a escola. Além disso, a educação inclusiva favorece não só o aluno com necessidades educacionais especiais, mas, também os demais alunos que passam a adquirir atitudes de respeito e compreensão pelas diferenças, além de juntos receberem uma metodologia de ensino diferenciada e da disposição de maiores recursos (FRIAS, 2008).

Nas palavras de Carvalho (2004):

A Letra das leis, os textos teóricos e os discursos que proferimos asseguram os direitos, mas o que os garante são as efetivas ações, na medida em que se concretizam os dispositivos legais e todas as deliberações contidas nos textos de políticas públicas. Para tanto, mais que prever há que prover recursos de toda a ordem, permitindo que os direitos humanos sejam respeitados, de fato. Inúmeras são as providências políticas, administrativas e financeiras a serem tomadas, para que as escolas, sem discriminações de qualquer natureza, acolham a todas as crianças, independentemente de suas condições físicas, intelectuais, sociais, emocionais, linguísticas ou outras.

Nessa esteira, para que a inclusão de alunos com deficiência intelectual no ensino regular se efetive, possibilitando o resgate de sua cidadania e ampliando suas perspectivas existenciais, não basta a promulgação de leis que determinem a criação de cursos de capacitação básica de professores, nem a obrigatoriedade de matrícula nas escolas da rede pública. Estas são, sem dúvida, medidas essenciais, porém não suficientes.

\section{REFLEXOS NA PRÁTICA DA INCLUSÃO PARA A CRIANÇA COM DEFICIÊNCIA INTELECTUAL: ESTUDO DE CASO}

Para maior compreensão da legislação aplicada ao caso concreto, foi rea- 
lizada pesquisa de campo. O Município de Alvorada permitiu a visita in loco à Escola Municipal por Ciclos de Formação Duque de Caxias, na qual foi possível analisar como a legislação é aplicada à prática durante uma aula observando uma turma com alunos de inclusão.

A escola é adequada para aplicação da pesquisa, porque os ciclos de formação possuem base legal que sustenta a organização dentro do ensino regular, conforme disposto no Art. 23 da Lei de diretrizes e Bases da Educação, que explicita:

Art. 23 A educação básica poderá organizar-se em séries anuais, períodos semestrais, ciclos, alternância regular de períodos de estudos, grupos nãoseriados, com base na idade, na competência e outros critérios, ou por forma diversa de organização, sempre que o interesse do processo de aprendizagem assim o recomendar.

Ou seja, cada escola poderá ter seu método organizacional para trabalhar o ensino, sendo todos estes métodos possíveis dentro do ensino regular de 9 (nove) anos.

Durante o período em sala de aula, foram observados os aspectos constantes nos objetivos do projeto de monografia, apresentado no segundo semestre de 2015, como: analisar a inclusão de menores com necessidades especiais no ensino regular e a aplicabilidade da legislação em vigor; relatar sobre a evolução da inclusão de menores com deficiência intelectual no ensino regular e descrever de que forma a legislação sobre o tema é implantada no sistema educacional brasileiro, bem como apontar a inefetividade da legislação aplicada à prática.

Para melhor avaliar a aplicabilidade da lei, além da observação em sala de aula, houve a aplicação de um questionário, respondido pelo educador que enfrenta o dia-a-dia de uma sala de aula cheia e com múltiplas dificuldades além das que competem ao aluno com deficiência intelectual.

\subsection{DEFICIÊNCIA INTELECTUAL E INCLUSÃO}

No caso em tela, foi observada a inclusão do aluno com deficiência inte- 
lectual, o aluno "Rafael", nome fictício aqui utilizado para melhor compreensão do trabalho, ele está matriculado em uma turma do $2 .^{\circ}$ ano do ensino regular.

"Rafael" possui laudo médico com o CID-10 (Classificação Internacional de Doenças) F 91.9, transtorno de conduta não especificado, e está fazendo avaliação médica, a pedido da coordenação pedagógica da escola que permitiu a pesquisa, referente ao CID-10 F 72, retardo mental grave.

O transtorno de conduta não especificado é caracterizado por padrões persistentes de conduta dissocial, agressiva ou desafiante. Tal comportamento deve comportar grandes violações das expectativas sociais próprias à idade da criança. Deve haver mais do que mau comportamento comum das crianças, se trata de um padrão duradouro de comportamento, por um período bem superior a seis meses, sendo descartados outros transtornos psicológicos (BALLONE, 2016).

O diagnóstico se baseia na presença de manifestações excessivas de agressividade e de tirania, crueldade com relação a outras pessoas ou a animais, destruição dos bens de outrem, crises de birra e de desobediência anormalmente frequentes e graves.

Em se tratando do retardo mental, é caracterizado pela parada do desenvolvimento ou desenvolvimento incompleto do funcionamento intelectual, caracterizados essencialmente por um comprometimento, durante o período de desenvolvimento, das faculdades que determinam o nível global de inteligência, isto é, das funções cognitivas, de linguagem, da motricidade e do comportamento social. $\mathrm{O}$ retardo mental pode acompanhar algum outro transtorno mental ou físico, ou ocorrer de modo independentemente (BALLONE, 2016).

O retardo mental grave é quantificado pelo índice de QI entre 20 e 40, aproximadamente. A maioria dos casos revela na fase adulta a idade mental de 3 a no máximo 6 anos. Em grande maioria dos portadores dessa deficiência intelectual deve ocorrer a necessidade de assistência contínua de forma permanente. 
No dia 20 de maio de 2016, foi observada a dinâmica da turma em que o "Rafael" foi inserido. Visualmente, "Rafael" teve dificuldades em se concentrar logo na chegada, importunando seus colegas enquanto derrubava os estojos deles e fazia menção a agredir os mesmos (punhos cerrados na altura da cabeça, mencionando a possibilidade de auferir soco aos colegas).

A turma do "Rafael", a turma B12, possui 27 alunos, incluindo ele, uma colega com microcefalia e outro com síndrome de down. Alguns destes alunos tiveram reação agressiva em forma de defesa, também dando a entender que poderiam machucar "Rafael", mas muitos colegas agem de forma protetora, o defendendo.

Assim que a turma se acalmou e "Rafael" se sentou, a professora deu início ás atividades. No dia em questão trabalhariam em cima do conto da "Chapeuzinho Vermelho", história escolhida para ensinar como as crianças devem se portar com estranhos. "Rafael" demonstrou interesse nos fantoches, entretanto, queria a atenção da professora só para ele. Ela tentou contornar a situação, mas "Rafael", além de atrapalhar a concentração de todos, saiu da sala correndo. A Professora chamou sua colega da sala ao lado para observar seus alunos, enquanto saía em busca de "Rafael".

"Rafael" estava sentado no pátio, olhando outras crianças brincarem na aula de Educação Física. A professora fez diversas propostas, conversou com "Rafael", até que o convenceu a retornar a sala. Ao "Rafael", foi disponibilizada uma caixa de brinquedo com peças de encaixe, onde poderia montar uma variedade de objetos, e assim se distrair e permitir que o fluxo da aula continuasse. Ficou brincando por aproximadamente $20 \mathrm{~min}$, até que um estagiário chegou para trabalhar com ele, assim como o monitor previsto em Lei deve fazer. Esta estagiária forneceu atividades de pintura e recorte, controlou "Rafael" em suas dispersões para que não atrapalhasse os colegas, nem a professora.

"Rafael”, por diversas vezes, foi agressivo com a estagiária, falou pouco e tentou fugir da sala. Com a saída de sua "monitora", após $2 \mathrm{~h}$ e $30 \mathrm{~min}$ de aula, também foi pedido para que eu encerrasse minhas atividades.

\subsection{ASPECTOS OPERACIONAIS ESCOLARES NA INCLUSÃO}

Uma vez por semana, na escola em questão, é disponibilizado atendi- 
mento psicopedagógico com a coordenadora da instituição para todos os alunos que possuam laudo médico de deficiência, ou estejam em processo de identificação de suas deficiências. Este atendimento não é em uma sala multifuncional, conforme o referido na Lei, mas sim no refeitório da escola, antes do horário do lanche das demais turmas.

O material didático é produzido pela própria coordenadora, utilizando os escassos recursos disponibilizados pelo Município.

A coordenadora apresentou a pasta do aluno. Nesta pasta havia várias atas de reuniões com a mãe e com a avó do menor. Alguns atestados médicos e o laudo, que comprovam a deficiência intelectual do aluno, estavam acompanhados do relatório feito pela professora de todas as crises apresentadas pelo Rafael no horário de aula. Essa foi a forma encontrada pela instituição de ter respaldo nos pedidos feitos á Secretaria de Educação do $\mathrm{Mu}$ nícipio em relação as garantias previstas em Lei.

Entende-se que o ensino público é carente de verbas e interesse político para assessorar e amparar a inclusão educacional, tendo em vista a situação precária em que se encontram as instituições públicas de ensino, pois essa situação se estende ás demais escolas do Município de Alvorada, assim como todos os outros municípios do estado do Rio Grande do Sul.

O monitor, previsto em Lei, não existe. Os estagiários de pedagogia, história e português, se dividem em 8 (oito) turmas que possuem alunos com deficiência. A estes estagiários não foram fornecidos curso de especialização para lidar com os menores com deficiência. Eles se dedicam a essa atividade apenas com o apoio e esforço da direção escolar.

A turma excede o número de alunos sugeridos de forma geral e a quantidade de alunos com necessidades especiais.

A professora da turma possui curso de LIBRAS, mas esta formação não é suficiente para lidar com as deficiências de "Rafael", nem de seus colegas também deficientes.

\subsection{REFLEXOS NO EDUCADOR POR CONTA DA INCLUSÃO DO EDUCANDO}

Foi realizado um questionário à professora da turma, a fim de compre- 
ender os reflexos da inclusão sob a ótica do educador, eis que é de suma importância para chegar a uma conclusão sobre a ineficácia da legislação acerca da inclusão de menores com deficiência intelectual no ensino regular.

Na primeira abordagem, buscou-se verificar o entendimento da professora sobre o que a legislação garante de apoio ao professor no processo de inclusão (Questão 1). Na compreensão da professora (entrevistada), não há uma garantia legal de apoio ao professor quando da inclusão de deficientes na educação regular. Nas próprias palavras da professora (entrevistada, 2016):

Acredito que a legislação ainda não oferece por completo esse apoio ao professor. Eu, Particularmente, não tenho conhecimento sobre isso. O pouco que sei, parece não ser posto em prática.

$\mathrm{Na}$ anterior analise dos dispositivos legais sobre o apoio ao professor no processo de inclusão de portadores de deficiências no ensino regular, notase que a Legislação dispõe sobre a necessidade da qualificação de profissionais da educação (formação continuada) para realizar a inclusão educacional adequada deste grupo no ensino regular. Mesmo assim, a professora entende que isso não dá muito apoio ao professor na inclusão educacional no ensino regular de portadores de deficiência.

Na sequência, questionou-se se a professora possui casos de inclusão em sua sala de aula e quais seriam as deficiências desses alunos (Questão 2). Na resposta da professora (entrevistada), em uma turma de 102 alunos, cinco deles são considerados formalmente deficientes, com prescrição médica, mas ainda há outros alunos na turma que não foram oficializados como deficientes:

[...] eu ministro aula para 102 alunos, desses, 5 possuem laudo médico e são oficialmente considerados como inclusão. No entanto, percebe-se que há mais casos cujos laudos ainda não foram investigados.

Estes outros alunos ainda carecem de análise de um profissional da área da saúde, em que pese a necessidade, muitas vezes, de tratamento específico para a necessidade apresentada a fim de garantir bem estar e saúde para a criança. 
Ao ser questionada se possui capacitação para trabalhar com alunos deficientes (Questão 3), a professora (entrevistada) revela não possuir curso especifico para ensinar alunos com necessidades especiais. Também informa que a maioria das vezes não há disponibilidade de especialização pelo órgão responsável (Município):

Não possuo preparação para autuar com alunos de inclusão, apenas realizei um curso básico de LIBRAS para oferecer um pouco a mais de qualidade. Infelizmente nem todo professor almeja isso ou tem condições de fazer, pois o investimento sai do próprio bolso.

Mesmo não havendo especialização, há interesse da professora (entrevistada) em adquirir conhecimento para melhor atender esse aluno especial. Dentro deste pensamento, foi questionado á ela se acha que, como professora, está preparada para lidar com os alunos deficientes (Questão 4):

Penso que sempre temos que estar nos atualizando e em busca de novidades. O preparo vem da nossa força de vontade em fazer a diferença na vida de cada criança.

Logo, entende-se que, apesar dos obstáculos, o professor tenta superar cada desafio, buscando externamente o apoio e o preparo que não lhe é concedido.

Para descobrir se a legislação em vigor é efetiva, foi abordado o entendimento da professora (entrevistada) acerca da inclusão conforme a previsão legal (Questão 5). Ela entende que:

Do meu ponto de vista a inclusão não ocorre como o previsto em Lei. Não é respeitado o limite de alunos por turma e a flexibilidade do currículo adaptado esbarra por falta de investimento.

Ainda neste ponto professora (entrevistada) respondeu como, na sua ótica, a inclusão deveria ser no que tange a legislação (Questão 6):

Para a Lei amparar melhor a inclusão o foco deve ser dado no preparo do professor, mesmo este ten- 
do que estar ciente que parte do esforço cabe a ele também.

Quanto à instituição de ensino (Questão 7), a professora (entrevistada) entende que o mesmo esforço dela, existe por parte da equipe diretiva e colegas para que a inclusão ocorra.

A escola oferece amparo para que ocorra inclusão, mas esbarra em questões as quais não têm autonomia para resolver, como verbas e relação com os pais dos alunos de inclusão. Na escola existem pessoas que auxiliam o professor em sala de aula, mesmo não sendo o que prevê a Lei, mas nos permite ministrar a aula com mais confiança.

No seguinte momento, foi questionada sobre os reflexos da inclusão para os alunos que não possuem deficiência alguma (Questão 8). Sua resposta foi a seguinte:

Mesmo a inclusão sendo uma barreira para a aprendizagem dos demais alunos, estes, muitas vezes, são afetivos e receptivos.

A seguir, para compreender o caso do aluno "Rafael", foi questionado para a professora (entrevistada), se a inclusão, mais especificamente, dos deficientes intelectuais graves, é benéfica ao deficiente e se ele apresenta desenvolvimento cognitivo quando incluído no ensino regular (Questão 9). Ela entende que:

Penso que para os casos de deficiência intelectual grave, a inclusão social deve ser o enfoque principal, pois não vemos, de certa forma, evolução na aprendizagem do aluno, mas este precisa aprender a conviver em sociedade.

Sendo assim, é possível dizer que a convivência com outras crianças é necessária, mas que a sala de aula não apresenta resultados no aprender deste aluno.

Por fim, quanto ao amparo do aluno deficiente proporcionado pela le- 
gislação em vigor (Questão 10), a professora (entrevistada) é objetiva ao dizer que deve haver atendimento especializado fora da sala aula:

Para melhor amparo do deficiente intelectual é necessário que haja a oferta de atendimento especializado paralelo com a escola, quando este aluno está incluído, e exclusivo quando este aluno precisa de uma atenção maior.

Após esse diálogo e a observação geral na visita in loco, nota-se que existe resistência dos professores e direções escolares, manifestadas através de questionamentos e queixas ou até mesmo com expectativas de que existam soluções mágicas, de aplicação imediata causando certa decepção e frustração, porque ela não existe, mesmo se esforçando ao máximo para superar a situação.

O problema se agrava quando o professor torna-se totalmente dependente de apoio ou assessoria de profissional da área da saúde, pois nesse caso a questão clínica se sobressai e novamente o pedagógico fica esquecido. Assim como no caso de Rafael, é necessário laudo médico para pleitear mais recursos para atendê-lo com a Prefeitura Municipal. Com isso o professor se sente desvalorizado e fora do processo por considerar esse aluno como doente concluindo que não pode fazer nada por ele, pois ele precisa de tratamento especializado da clínica. O professor se esquece do seu papel, porque não é considerada sua formação, as condições da própria escola em receber esses alunos, que entram nas escolas e continuam excluídos de todo o processo de ensino-aprendizagem e social, causando frustração e fracassos, dificultando assim a proposta de inclusão.

Por um lado os professores julgam-se incapazes de dar conta dessa demanda, despreparados e impotentes frente a essa realidade que é agravada pela falta de material adequado, de apoio administrativo e recursos financeiros.

O professor entra em aula desanimado e não vê expectativa de evolução da aprendizagem do aluno com deficiência intelectual. Pode parecer antiético, mas o professor suspira de alívio quando entra um terceiro para lidar com o deficiente enquanto ele tenta, exaustivamente, ministrar sua aula. 
REVISTA DA ESDM - 2016 - V 2-N.04

\subsection{REFLEXOS NO EDUCANDO DEFICIENTE INTELECTUAL}

O aluno com deficiência intelectual, assim como o "Rafael", nas condições apresentadas, não possui capacidade de integração e socialização em uma sala de aula de ensino regular. Por se tratar de um caso grave, não possui capacidades cognitivas de aprender em uma turma nas mesmas condições dos demais alunos. Nota-se que foi, em tese, negligenciado na atenção e no trabalho proposto, pois o educador não atendeu a limitação desse deficiente intelectual.

Aparentemente não existe aproveitamento do aluno pelo que lhe foi proposto. A inclusão o excluiu da dinâmica da aula, porque necessita de um atendimento exclusivo e capacitado ás suas necessidades.

Não há como saber como a situação se apresenta para o aluno. A única evidência que deixa transparecer é a carência de atenção.

\subsection{REFLEXOS NOS EDUCANDOS SEM DEFICIÊNCIA INTELEC- TUAL}

Os alunos da turma B12 evitam o "Rafael", demonstram medo pelo que ele pode fazer e, assim como ele, a maioria reage de forma agressiva ao contato dele.

Na situação observada, é fácil para os demais alunos da turma, que não possuem deficiência, ficarem dispersos e terem dificuldade de aprendizagem, já que a qualquer momento a aula pode ser interrompida pela necessidade de "Rafael" de ter atenção, ou então de chamar a atenção da professora fugindo da aula.

Ouvi, durante a fuga de "Rafael", uma colega sua que sentava mais próxima de mim, a expressão "Que saco! Agora a "prô" vai demorar a voltar. Queria ouvir a história”. Uma clara manifestação de que essa é a rotina da turma, bem como é frustrante para os colegas serem interrompidos em suas atividades.

Não restam duvidas que estes alunos possuem maior dificuldade de aprendizagem do que alunos em turma sem deficientes intelectuais no nível de "Rafael". Lógico que a inclusão não é impossível, mas em casos como es- 
te, de uma deficiência mais atenuada, se torna complicado e delicado incluir uma criança que não obterá aproveitamento do que lhe é proposto e ainda será obstáculo para aprendizagem dos demais.

Esses reflexos são observados de forma geral, em praticamente todos as escolas municipais que enfrentam a inclusão sem preparo algum.

\section{CONSIDERAÇÕES FINAIS}

Conclui-se que para o processo de inclusão escolar é preciso que haja uma transformação no sistema de ensino que vem beneficiar toda e qualquer pessoa, levando em conta a especificidade do sujeito, assim como as suas deficiências e limitações.

Conforme as hipóteses trabalhadas no projeto em resposta ao questionamento: Em que medida a legislação que regulamenta a inclusão dos menores com deficiência intelectual no ensino regular é efetiva no Brasil? Temos que há necessidade de suplementação normativa nos Estados e Municípios da legislação em apreço, com o escopo de que tais entes federados disciplinem em face de suas peculiaridades a prática pedagógica pelos educadores no âmbito de menores com deficiência intelectual no ensino regular.

É preciso que o legislador observe a necessidade que cada grau de deficiência irá impor para aprendizagem. Não são todos os menores com deficiência intelectual que terão aproveitamento no seu desenvolvimento cognitivo e educacional regular.

Para que a inclusão seja uma realidade, será necessário rever uma série de barreiras, além da política e práticas pedagógicas e dos processos de avaliação. É necessário conhecer o desenvolvimento humano e suas relações com o processo de ensino aprendizagem, levando em conta como se dá este processo para cada aluno.

Deve ser utilizado o apoio novas tecnologias e investir em capacitação, atualização, sensibilização, envolvendo toda comunidade escolar. Focar na formação profissional do professor, que é relevante para aprofundar as discussões teóricas práticas, proporcionando subsídios com vistas à melhoria do processo ensino aprendizagem.

Assessorar o professor para resolução de problemas no cotidiano na sala 
REVISTA DA ESDM - 2016 - V 2-NO24

de aula, criando alternativas que possam beneficiar todos os alunos. Utilizar currículos e metodologias flexíveis, levando em conta a singularidade de cada aluno, respeitando seus interesses, suas ideias e desafios para novas situações. Investir na proposta de diversificação de conteúdos e práticas que possam melhorar as relações entre professor e alunos. Avaliar de forma continuada e permanente, dando ênfase na qualidade do conhecimento e não na quantidade, oportunizando a criatividade, a cooperação e a participação.

Valorização maior das metas e não dos obstáculos encontrados pelo caminho, priorizando as questões pedagógicas e não apenas a questão biológica, com expectativa de que tudo será resolvido pela saúde.

Falta a sensibilidade do legislador quanto á prática da inclusão, para que a normativa desta seja efetiva e ideal para aplicação.

Não existe nenhuma proposta de inclusão que possa ser generalizada ou multiplicada, pois ainda é incipiente, no entanto é de consenso que esse processo é de responsabilidade de toda a sociedade e por tanto é preciso que a escola esteja aberta, favorecendo assim, as trocas para a construção do processo de inclusão escolar.

\section{REFERÊNCIAS BIBLIOGRÁFICAS}

ARANHA, Maria Salete Fábio. Projeto Escola Viva: garantindo o acesso e permanência de todos os alunos na escola: necessidades educacionais especiais dos alunos. Brasília: Ministério da Educação, Secretaria de Educação Especial, 2005. 5 v.

BALLONE, Geraldo José. Psiqueweb: Portal da psiquiatria geral. Disponível em: <http:// www.psiqweb.med.br/site/DefaultLimpo.aspx?area=ES/VerClassificacoes\&idZ Classificacoes $=65>$. Acesso em: 23 mai. 2016.

BRAGA, Adelaide Maria Melo. Inclusão escolar de alunos com deficiência intelectual em escolas regulares. Teresina: Universidade Federal do Piauí, 2010.Disponível em: <http://www.ufpi.br/subsiteFiles/ppged/arquivos/files/VI.encontro.2010/ GT.11/GT11122010.pdf>. Acesso em:24 ago. 2015.

BRASIL. Constituição (1988). 9a Ed. Porto Alegre: Verbo Jurídico, 2013.

Senado Federal. Lei de Diretrizes e Bases da Educação Nacional: n. ${ }^{\circ}$ 9394/96. Brasília: 1996. Disponível em: <http://portal.mec.gov.br/arquivos/pd f/ldb.pdf > Acesso em: 16 de ago. 2015. 
.CORDE. Comitê de Ajudas Técnicas. Ata 7. Disponível em: <http://www.Mj.gov. br/corde/arquivos/doc/Ata_VII_Reuniao_doComitê_de_Ajudas_Tecnicas.doc> Acesso em: 16 de mai. 2016.

BRASIL, Ministério da Educação, Secretaria de Educação Especial. Projeto Escola Viva: Garantindo o acesso e permanência de todos os alunos na escola - Alunos com necessidades educacionais especiais, Brasília: MEC/SEESP, 2000, vol. 6 .

Projeto Escola Viva: Garantindo o acesso e permanência de todos os alunos na escola: Alunos com necessidades educacionais especiais - Adaptações Curriculares de Grande Porte, Brasília: MEC/SEESP, 2005, vol. 5.

Saberes e práticas da inclusão: recomendações para a construção de escolas inclusivas. 2 ed. Coordenação geral SEESP/MEC. Brasília: MEC, Secretaria de Educação Especial. 2006. Disponível em: <http://portal.mec.gov.br/seesp/arquivos/pdf/ const_escolasinclusivas.pdf $>$. Acesso em: 13 nov. 2015.

BRASIL. Decreto Executivo 6949/2009. Promulga a Convenção Internacional sobre os Direitos das Pessoas com Deficiência e seu Protocolo Facultativo, assinados em Nova York, em 30 de março de 2016. Disponível em: <http://www .planalto.gov.br/ccivil _03/_ato2007-2010/2009/decreto/d6 949.htm>. Acesso em:24 ago. 2015.

BRASIL. Decreto Legislativo n. 186 de 2008. Aprova o texto da Convenção sobre os Direitos das Pessoas com Deficiência e de seu Protocolo Facultativo, assinados em Nova Iorque, em 30 de março de 2007. Disponível em: <http://ww w.planalto.gov.br/ ccivil_03/Constituicao/Congresso/DLG/DLG-186-2008.htm> Acesso em: 24 ago. 2015.

BRASIL. Decreto n. ${ }^{\circ}$ 6.253, de 13 de novembro de 2007. Dispõe sobre o Fundo de Manutenção e Desenvolvimento da Educação Básica e de Valorização dos Profissionais da Educação - FUNDEB, regulamenta a Lei n ${ }^{\circ} 11.494$, de 20 de junho de 2007. Disponível em: <https://www.planalto.gov.br/ccivil_03/_Ato2007-2010/2007/Decreto/ D6253.htm>. Acesso em: 22 mai. 2016.

BRASIL. Decreto Legislativo n. ${ }^{\circ} 7.611$ de 17 de novembro de 2011. Dispõe sobre a educação especial, o atendimento educacional especializado e dá outras providências. Disponível em: <http://www.planalto.gov.br/ccivil_03/_ato2011201 4/2011/decreto/ d7611.htm>. Acesso em: 19 mai. 2016.

BRASIL. Decreto regulamentador da Lei 7853 de 89 . Decreto n. ${ }^{\circ} 3289$ de 20 de dezembro de 1999. $9^{\mathrm{a}}$ Ed. Porto Alegre: Verbo Jurídico, 2013

BRASIL. Lei 8069 de 13 de julho de 1990. Estatuto da Criança e do Adolescente. 9. ${ }^{\text {E }}$ Ed. Porto Alegre: Verbo Jurídico, 2013.

BRASIL. Lei de Diretrizes e Bases da Educação Nacional. Lei 10172 de 09 de janeiro de 
2001. 9. Ed. Porto Alegre: Verbo Jurídico, 2013.

BRASIL. Lei n. 9.394, de 20 de dezembro de 1996. Disponível em: $<$ http://www.planalto. gov.br/CCIVIL 03/leis/L9394.html> Acesso em: 24 ago. 2015.

BRASIL. SEESP/SEED/MEC. A Educação Especial na Perspectiva da Inclusão Escolar: A Escola Comum Inclusiva. Fascículo I. Brasília. 2010.

BRASIL. A Educação Especial na Perspectiva da Inclusão Escolar: O Atendimento Educacional Especializado para Alunos com Deficiência intelectual. Fascículo II. Brasília. 2010.

CARVALHO, Rosita Édler. Educação Inclusiva: Com os Pingos nos “is". Porto Alegre: Mediação, 2004.

Declaração de Salamanca: Sobre Princípios, Políticas e Práticas na Área das Necessidades Educativas Especiais. Espanha, 1994. Disponível em: <http://portal.mec.gov.br/ seesp/arquivos/pdf/salamanca.pdf $>$. Acesso em: 20 out. 2015.

ESCOBAL, Giovana; ROSSIT, Rosana Aparecida Salvador; GOYOS, Celso. Aquisição de conceito de número por pessoas com deficiência intelectual. Psicologia em Estudo, v. 15, n. 3, p. $467-475,2010$.

FRIAS, Elzabel Maria Alberton. Inclusão escolar do aluno com necessidades especiais: contribuições ao professor do Ensino Regular. Paraná, 2008.Disponível em: <http:// www.diaadiaeducacao.pr.gov.br/portals/pde/arquivos/1462- 8.pdf $>$. Acesso em: 16 mai. 2016.

JAEGER, Werner Wilhelm, 1888-1961. Paideia: a formação do homem grego. Trad. Ar-

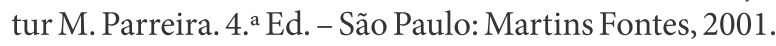

MANTOAN, Maria Teresa Eglér. A Integração de pessoas com deficiência: contribuições para uma reflexão sobre o tema. São Paulo: Memnon, 1997.

MAZZOTTA, M. J. S. Educação Especial no Brasil: História e políticas públicas. 5. ed. São Paulo: Cortez, 2008.

.Educação Especial no Brasil: histórias e políticas públicas. São Paulo - Cortez, 1996.

MELLO, Celso Antônio Bandeira de. O conteúdo jurídico do princípio da igualdade. 3. ed.7. tiragem. atual. São Paulo: Malheiros, 1999.

MENDES, E. G. A radicalização do debate sobre a inclusão escolar no Brasil. Revista Brasileira de Educação, Rio de Janeiro, v.11, n. 33, p. 405, dezembro. 2006.

MINISTÉRIO DA EDUCAÇÃO, Gabinete do Secretário de Estado da Educação. Despacho n. ${ }^{\circ}$ 14.026/2007. Brasília: Diário da República, 2.a série, n. ${ }^{\circ}$ 126, 3 de Julho de 2007. 
- A INEFETIVIDADE DA LEGISLAÇÃO ACERCA DA INCLUSÃO DE CRIANÇAS COM DEFICIÊNCIA INTELECTUAL NO ENSINO REGULAR

OLIVEIRA, Romulo André Alegretti de. Ensino Jurídico no Brasil: Qualidade e Risco. Passo Fundo: Universidade de Passo Fundo, 2003. 145 p.

PEREIRA, Marilú Mourão. Inclusão escolar: Um desafio entre o ideal e o real. Campo Grande: Portal da Educação, 2008. Disponível em: <http://www.portaleducacao. com.br/pedagogia/artigos/2284/inclusao-escolar-um-desafio-entre-o-ideal-e-oreal\#ixzz48qwg1Hzw> Acesso em: 17 mai. 2016.

ORGANIZAÇÃO MUNDIAL DA SAÚDE. Classificação Estatística Internacional de Doenças e Problemas Relacionados à Saúde - CID-10. Classificação de transtornos mentais e de comportamento da CID-10: descrições clínicas e diretrizes diagnósticas. Porto Alegre: Artmed, 1993.

PIAGET, J. \& INHELDER, Barbel. A psicologia da criança. 72 ed. São Paulo, DIFEL, 1982.

SARTORETTO, Maria Lúcia; BERSCH, Rita. Atendimento Educacional Especializado - AEE. Assistiva Tecnologia e educação: 2014. Disponível em: <http://www. assistiva.com.br/aee.html>. Acesso em: 22 mai. 2016.

SÃO PAULO. MEC/SEESP. Política Nacional de Educação Especial na Perspectiva na Educação Inclusiva. Portaria Ministral n. ${ }^{\circ} 555$ de 5 de junho de 2007 São Paulo: MEC, 2007. $15 \mathrm{p}$.

TÉDDE, Samantha. Crianças com Deficiência Intelectual: A Aprendizagem e a Inclusão. Americana: Centro Universitário Salesiano de São Paulo, 2012.90 p.

VALERA, Juliessa Ricce. Deficiência Intelectual e Adaptação Curricular Sob o Olhar de Teses e Dissertações. Araraquara: Universidade Estadual Paulista - UNESP, 2015. 168 f. Disponível em: <http://wwws.fclar.unesp.br/agenda-pos/educacao_escolar/ 3417.pdf $>$. Acesso em: 24 ago. 2015

XAVIER, Amanda Vanessa de Oliveira. A Inclusão da Pessoa com Deficiência na Escola Regular. Artigo para obtenção do título de licenciatura em Pedagogia apresentado ao Curso de Pedagogia da Faculdade de Educação da Universidade Federal da Grande Dourados, orientado pelo Prof ${ }^{\circ}$ Dr. Warley Carlos de Souza. Disponível em: $<>$. Acesso em: 24 jun. 2015. 